\title{
Effects of overtraining on reversal and half-reversal shift performance employing aural stimuli*
}

\author{
CHARLES L. RICHMAN $\dagger$ and LEON LORENC \\ Wake Forest University, Winston-Salem, North Carolina 27109
}

\begin{abstract}
The effect of overtraining a set of nonsense sounds on a reversal and half-reversal shift was investigated. Overtraining facilitated reversal but not half-reversal shift performance. These results confirmed previous findings using visually presented stimuli.
\end{abstract}

Recent research has been concerned with the formation of stimulus organization in stimulus sets not discriminable on the basis of known attributes (Richman \& Trinder, 1968; Trinder, Metzger, Sherman, \& Richman, 1972; and, Richman, Bidwell, \& Hynson, 1974). In these studies the only defining characteristic of a stimulus set was the common terminal response assigned to each stimulus member. Two stimulus sets were composed of four 16-point nonsense figures. Ss were either nonovertrained or overtrained prior to a reversal or half-reversal shift. In each of these studies it was demonstrated that as the amount of preshift training increased, trials to reversal shift criteria decreased with little or no change in half-reversal shift performance. These results suggested that a necessary condition for producing stimulus organization, which was inferred from the more rapid reversal than half-reversal shift performance, was overtraining a set of unrelated stimuli having a common terminal response.

Although the relative rates of aural vs visual learning and memory have been the subject of a number of investigations (Murdock \& Waller, 1969; Rollins, 1972; Lieberman \& Culpepper, 1965; Dornbush \& Basow, 1970; and, Dornbush, 1970) little is known about the formation of unrelated aural stimuli into functionally related organized units.

The present study was designed to investigate the relationship between extent of preshift training and type of shift using nonsense sounds as stimuli.

\section{METHOD}

\section{Subjects}

The Ss were 28 male and 12 female undergraduate students enrolled in first year psychology courses at Wake Forest University. Seven male and 3 female Ss were assigned to each of the four experimental groups.

*This research was supported by funds from U.S. Public Health Service Grant MH-21288 from the National Institute of Mental Health and the Wake Forest University Research and Publication Fund. The authors would like to thank Robert C. Beck for his helpful comments on the manuscript.

tR equests for reprints should be sent to Charles L. Richman, Department of Psychology, Wake Forest University, Winston-Salem, North Carolina 27109.

\section{Procedure}

The stimuli were four runs (four groups of notes) consisting of five notes each. All notes were selected from the middle octave of a Wurlitzer piano (from middle $\mathrm{C}$ to $\mathrm{C}^{\prime}$ ) and recorded on a Craig tape recorder. The second note in each run was a sharp and the fourth one was a flat. The notes within a particular run remained in the same sequential order throughout the experiment. Run presentations were randomized. Notes were played for a 1 -sec duration with a 20 -msec internote interval, a 5 -sec interrun interval and a $12-\mathrm{sec}$ intertrial interval. A trial consisted of the presentation of all four runs.

The Ss were run individually. A response box with a centrally located green reinforcement light and "left" and "right" response buttons placed to the left and right of the reinforcement light was placed in front of the S. The E's control panel and response-reinforcement data sheet informed the $\mathrm{E}$ as to whether or not the S's responses were correct. The control panel was connected to the S's response buttons and reinforcement light; the panel indicated which response button the $\mathrm{S}$ depressed and a reinforcement button controlled the S's reinforcement light. Immediately following a correct response, the $\mathrm{E}$ activated the reinforcement light for a $1.0-\mathrm{sec}$ duration.

The Ss were told they were participating in a learning experiment in which they had to learn the association between the different sounds presented, and one of the two responses. They were instructed to depress either left or right response button immediately following a complete sound presentation of five notes in succession at which time a green light flash would indicate they had the correct response. To dispel any notion that the equipment would malfunction the Ss were informed that the apparatus had worked flawlessly for the last 3 years.

The experimental design consisted of a 2 by 2 factorial with two types of shift (reversal and half-reversal) and two levels of training (criterion, one perfect trial; and, overtraining, three consecutive perfect trials). Shift criterion was set at one perfect trial. Ss were randomly assigned to one of the four subgroups. A reversal shift was accomplished by reversing all four stimulus run-response contingencies; whereas, a half-reversal shift was accomplished by changing one "left" association to "right" and one "right" association to "left." Therefore, during a reversal shift all stimulus-response associations were changed, while during a half-reversal shift, only half of the stimulus-response associations were changed. In line with the suggestion by Slamecka (1968), the correct stimulus-response associations were identical for the reversal and half-reversal shift groups during the shift phase and therefore different during original training.

\section{RESULTS AND DISCUSSION}

A training by shift analysis of variance was conducted on the number of trials to original learning criterion. For 
both the training and training by shift analysis, $\mathrm{F}$ ratios were less than 1.00; however, Ss trained under the reversal shift condition took a greater number of trials to reach a one perfect trial original learning criterion than those trained in the half-reversal shift condition $[F(1,36)$ $=8.98, \mathrm{p}<.01]$. Table 1 presents the mean trials to original and shift criterions (one perfect trial) for the four experimental groups. The shift results shown in Table 1 indicate that overtraining facilitated a reversal shift but failed to affect half-reversal shift performance. A training by shift analysis of variance performed on the shift trials to criterion scores showed that the main effects of training and shift were not statistically significant $(\mathrm{Fs}<1.00)$; however, the Training by Shift interaction was found to be significant $[F(1,36)=6.84$, $p<.025]$. Pairwise $F$ tests showed that: (1) Following criterion training, reversal and half-reversal shift groups were statistically equivalent $[F(1,18)=1.75, p>.20]$. (2) In the overtraining condition, a reversal shift was accomplished in fewer trials than a half-reversal shift $[F(1,18)=6.91, p<.025],(3)$ while overtraining failed to facilitate half-reversal shift performance $[\mathrm{F}(1,18)=$ 1.73, $\mathrm{p}>.20$ ] (4) overtraining did facilitate reversal shift performance $[F(1,18)=5.71, p<.05]$.

The facilitation of reversal but not half-reversal shift performance as a function of overtraining sets of unrelated sounds is clearly consistent with previous investigations using visually presented stimuli (Richman \& Trinder, 1968; and, Richman, 1973). In the present study, stimulus organization (unitization) was inferred from the finding that overtraining facilitated reversal shift performance but had little effect on half-reversal shift behavior. According to a simple S-R analysis of the present procedures, half-reversal shift performance should be more rapid than reversal shift behavior since only half the S-R association are changed in the former, but all the associations are changed in the latter shift condition. With overtraining, however, reversal shifts were facilitated suggesting that during extended training Ss learn something more than S-R associations. It is suggested here that overtraining allows the Ss enough total time (see Richman, Bidwell, \& Hynson, 1974) to form mediational responses to the stimulus runs associated with a common terminal response (Kendler \& Kendler, 1962). Having formed a mediational response, it is a simple matter for the $\mathrm{S}$ to change the overt response while retaining the common mediator. Half-reversal shift performance fails to improve with overtraining because the "old" mediators must be discarded and "new" ones formed. Representational
Table 1

\begin{tabular}{|c|c|c|c|c|}
\hline \multirow{2}{*}{ Mean } & \multicolumn{2}{|c|}{ Nonovertraining } & \multicolumn{2}{|c|}{ Overtraining } \\
\hline & Original & Shift & Original & Shift \\
\hline Reversal Shift & 7.1 & 7.0 & 7.2 & 3.0 \\
\hline Half-Reversal Shift & 3.9 & 4.4 & 2.9 & 6.6 \\
\hline
\end{tabular}

coding of runs possessing a common terminal response in the overtrained groups were common place. Overtrained Ss offered the following comments following the conclusion of the experimental session, "The 'right' sounds sounded like a soap opera theme," "The "lefts' were smooth," "The two 'left' sounds were sharps," etc.

In conclusion, we suggest that facilitation of a reversal shift occurs as a function of overtraining because the Ss had formed a functional unit made up of the two runs possessing a common terminal response. The reversal of associations to these two units is as simple as reversing two stimuli. The half-reversal shift problem is not facilitated by overtraining because the $S$ is required to "break up" units and discard mediational responses in order to learn the shift problem.

\section{REFERENCES}

Dornbush, R. L. Attention in biserial simultaneous short-term memory. Perception \& Psychophysics, 1970, 7, 4, 244-246.

Dornbush, R. L., \& Basow, S. The relationship between auditory and visual short-term memory and reading achievement. Child Development, 1970, 41, 4, 1033-1044.

Kendler, H. H., \& Kendler, T. S. Vertical and horizontal processes in problem solving. Psychological R eview, 1962, 69, 1-16.

Lieberman, L. R., \& Culpepper, J. T. Words vs objects: Comparison of free verbal recall. Psychological R eports, 1965 , 17(3), 983-988

Murdock, B. B., Jr. \& Waller, K. D. Modality effects in free recall. Journal of Verbal Learning \& Verbal Behavior, 1969, 8, 665-676.

Richman, C. L. Role of overtraining in reversal and conceptual shift behavior. Journal of Experimental Psychology, 1973, 99, 2, 285-287.

Richman, C. L., Bidwell, L., \& Hynson, K. Effects of temporal factors on reversal and half-reversal shifts. American Journal of Psychology, 1974, in press.

Richman, C. L. \& Trinder, J. Effect of a novel stimulus dimension on discrimination learning. Journal of Experimental Psychology, 1968, 77, 163-165.

Rollins, H. A. Serial position effects of simultaneous bisensory memory. Journal of Experimental Psychology, 1972, 2, 162-167.

Slamecka, N. J. A methodological analysis of shift paradigms in human discrimination learning. Psychological Bulletin, 1968, 69(6), 423-438.

Trinder, J., Metzger, K. R., Sherman, A. E., \& Richman, C. L. Development of stimulus organization. Developmental Psychology, 1972, 6, 26-31.

(R eceived for publication August 22, 1974.) 